\title{
A Switching Fuzzy Controller for Induction Motors with Self-tuning Capability
}

\author{
F.Barrero, A.Torralba, E.Galván and L.G.Franquelo \\ E.T. Superior de Ingenieros \\ Univiversidad de Sevilla \\ Avda Reina Mercedes s/n \\ C.P. 41012 Sevilla, Spain \\ e-mail: fbarrero@gtex02.us.es
}

\begin{abstract}
Fuzzy-logic based controllers have been recently proposed to implement vector control methods in induction motors. This paper presents a new switching self-tuning type of fuzzy controller aimed at obtaining a satisfactory performance (rise time and overshoot) in the motor response. Two fuzzy controllers, a PI-like fuzzy controller and a PD-like fuzzy controller are applied in different regions of the control space. Their responses are combined by another fuzzy inference machine which divides the control surface in a fuzzy way. Also a simple adaptive fuzzy system have been used to tune the proposed controller to provide a simple way to redefine the controller and obtain a better control action. Simulation results show that this scheme has the ability to improve the transient and steady state performance of the controlled system from the simple PD-like and PI-like fuzy controllers. The scheme has been implemented using a DSP and the simulation results have been experimentally validated.
\end{abstract}

\section{INTRODUCTION}

The induction motor is a complex, non-linear system, with time-varying parameters. Different control strategies have been proposed to simplify the control of induction motors, such as Vector Control methods. Unfortunately, a set of time-varying parameters, such as inertia, torque and rotor resistance, can severely affect the dynamic performances, so that some kind of robustness or adaptativity is required [1].

Robustness is an inherent characteristic of fuzzy logic based controllers which is of great importance where dealing with Induction Motors, as it was shown in [2]. The optimal design of fuzzy controllers is not a trivial problem. A practical approach uses the set of Mandani rules and heuristically tries to adjust the controller gain and the scaling factors of the input variables.

Recently a simple fuzzy self--tuning system for Induction Motor Controller, based on a PI-like Fuzzy Controller was proposed [9]. The scaling factors of the inputs (the speed error and the integral speed error) were changed using fuzzy rules to achieve a good transient response. A conflict arises when trying to obtain a mini- mal overshoot with a minimum rise time because there are only two variables (two scaling factors) to tune the controller.

This paper presents a new switching type of fuzzy controller and a method for the automatic tuning of the controller parameters. The presented method performs iteratively until a desired value for the response time is achieved with minimal overshoot. The proposed controller outperforms the simple PI-like controller of [9]. Besides, there are four variables (four scaling factors) which can be modified to obtain the desired system response, achieving a faster adaptation.

Although this method is mainly intended for the initial tuning of the controller, it can be used on-line in those cases where the induction motor is continously operated in an start/stop process, e.g., in elevators.

The paper is structured as follows. In next section, a simple analysis is used to explain the advantages of the proposed fuzzy control system. Section III briefly reviews the operation of the fuzzy-rule adaptation mechanism. Section IV presents simulation and experimental results. The conclusions are in the final section.

\section{SWitching CONTROL SYSTEM}

The structure of the control system is shown in figure 1. In this figure, the Indirect Vector Control method (IVC) is used, which is described elsewhere [1]. The flux component of the stator current $i_{d}^{c}$ is maintained constant, while the output of the fuzzy controller is the desired torque component of the stator current $i_{q}^{e}$.

The error between the desired speed $w_{\text {ref }}$ and the measured rotor speed $w_{r}$, the integral speed error and the change in the error, are the inputs to a PI-like fuzzy controller and a PD-like fuzzy controller. The control actions are combined by means of a weighting factor $\alpha$ which is the output of a supervisory fuzzy inference. The supervisory fuzzy inference machine acts as a hig- 


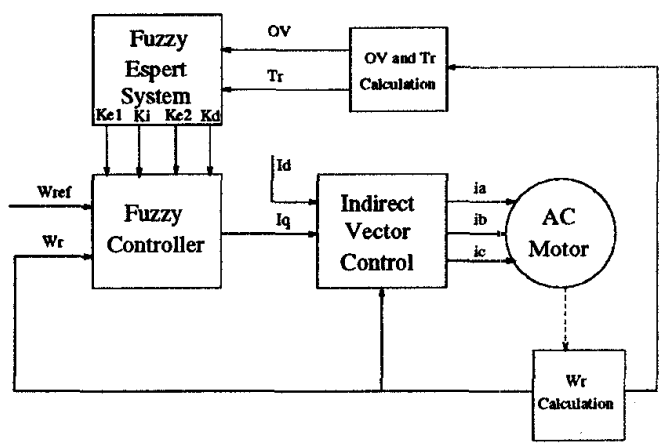

Figure 1: Fuzzy Control block diagram.

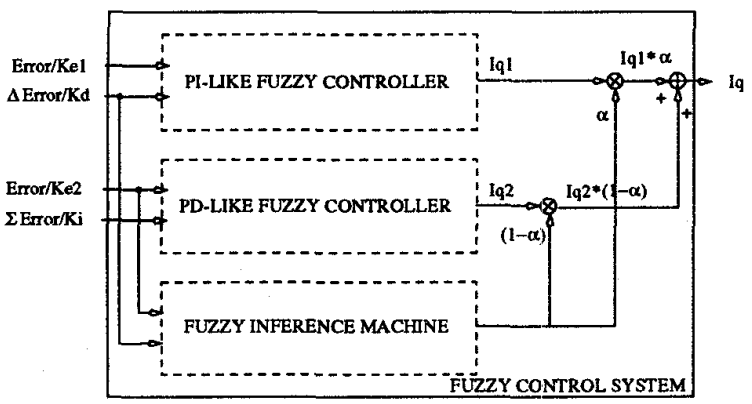

Figure 2: Switching Fuzzy controler.

her hierarchical level of control. It divides the control region depending on the speed error and change in error. Figure 2 depicts the block diagram of the proposed hierarchical fuzzy control. Membership functions are depicted in figure 3 .

The final actuation $i_{q}$ is as follows:

$$
i_{q}=\alpha \cdot i_{q 1}+(1-\alpha) \cdot i_{q 2}
$$

where $i_{q 1}$ is the control action given by the PI-like fuzzy controller, $i_{q 2}$ is the control action given by the PDlike fuzzy controller. $\alpha$ is the output of the supervisory fuzzy inference machine.

\section{FUZZY EXPERT SYSTEM FOR THE AUTOMATIC TU- NING}

An analogous system to that described in [9] has been used. The adaptive mechanism is carried-out by altering the scaling factors of the input variables of the main fuzzy system. The expert system is implemented by means of a fuzzy controller whose rules are depicted in figure 4. Its inputs are the rotor speed overshoot (ov) and the rise time $\left(t_{r}\right)$, which are computed in a preprocessing block. Changes in the scaling factors of the input variables of the main fuzzy controllers $\left(K_{e 1}\right.$ and

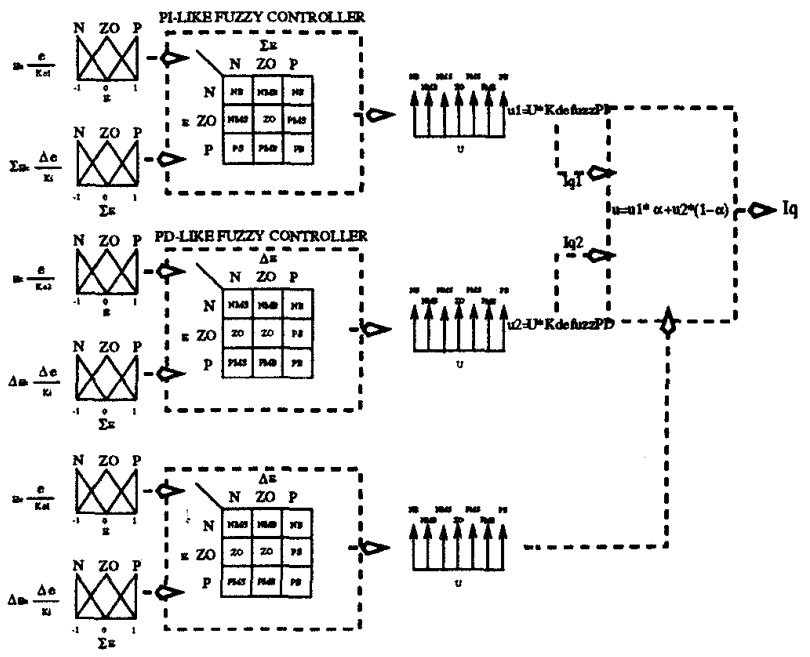

Figure 3: Rules and membership functions of the controller.

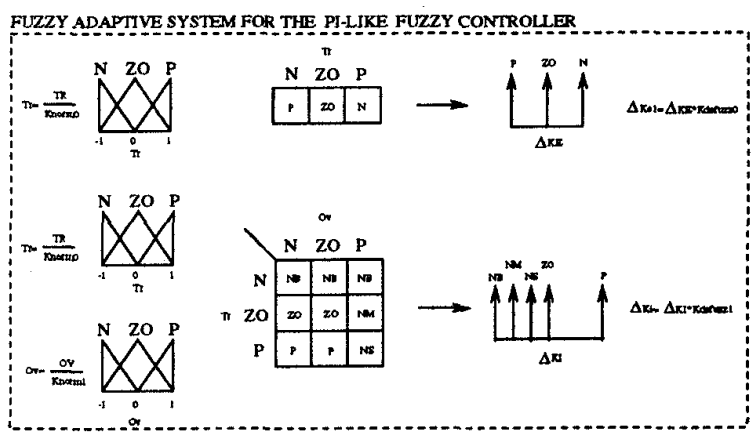

FUZZY ADAPTIVE SYSTEM FOR THE PD-LIKE FUZZY CONTROLLER

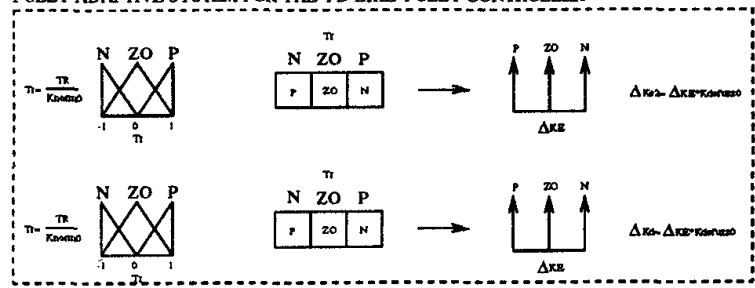

Figure 4: Rules and membership functions of the adaptive fuzzy expert system.

$K_{i}$ for the PI-like fuzzy controller, and the $K_{e 2}$ and $K_{d}$ for the PD-like fuzzy controller) are the outputs of the expert fuzzy system.

\section{EXPERIMENTAL RESULTS}

An Induction Motor of nominal characteristics equal to that used in experiments, has been simulated. The nominal characteristics of the Induction Motor used in simulations and experiments are shown in table 1. Figure 5 shows simulation results obtained when different control methods are compared. It shows the simulation response when a $\mathrm{PI-like} \mathrm{fuzzy}$ controller is used, when a PD-like fuzzy controller is used and when both, the PD-like and the PI-like fuzzy controllers simulated before, are combined in the proposed way. The response is better in the last case. 


\begin{tabular}{|c|c||c|c|}
\hline$L_{m}(H)$ & 2.0642 & $R_{s}(\Omega)$ & 24.45 \\
\hline$L_{s}(H)$ & 2.0888 & $R_{r}(\Omega)$ & 41.774 \\
\hline$L_{r}(H)$ & 2.0887 & $p$ & 2 \\
\hline
\end{tabular}

Table 1: Induction Motor nominal parameters.

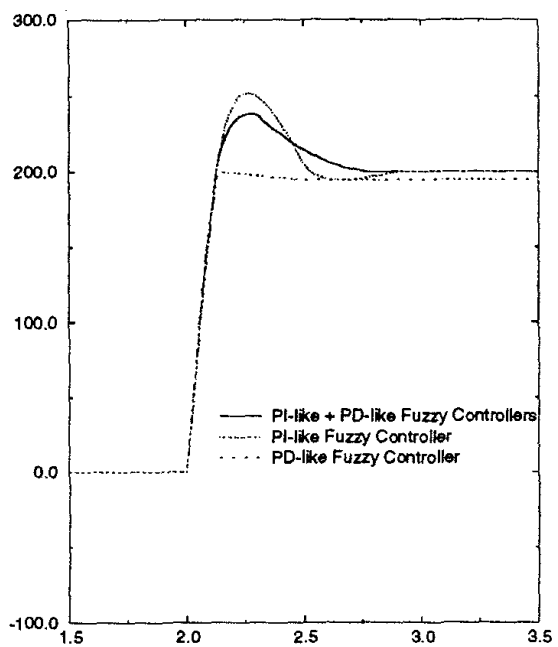

Figure 5: Simulation results. Induction Motor controlled by (a) A PI-like + PD-like Fuzzy Control System, (b) A Simple PI-like Fuzzy Control System and (c) A Simple PD-like Fuzzy Control System.

To prove the abilities of the presented method, the controller of figure 1 has been implemented using a floating point Digital Signal Procesor TMS320C30 alongside a PC 386 used for the adaptive process and data adquisition.

Figure 6 shows how the proposed hierarchical fuzzy control system performes, as well as the adaptive process applied to the Induction Motor. Note that the desired

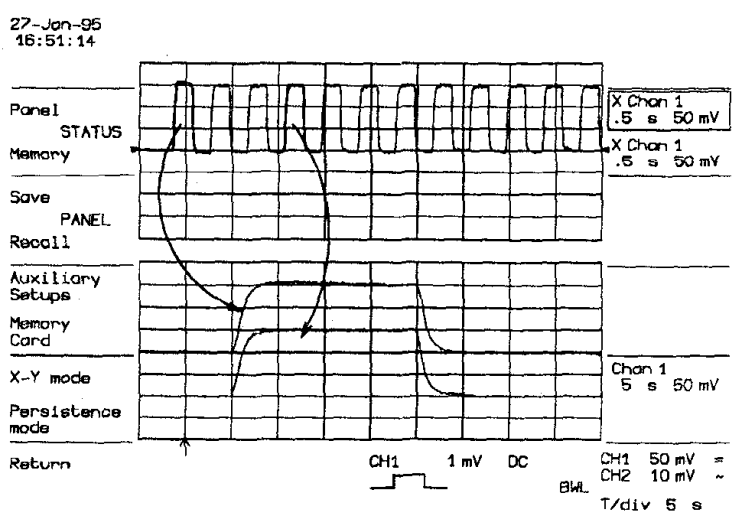

Figure 6: Experimental Adaptive process applied to the Induction Motor controlled using the Mixed Fuzzy Control System

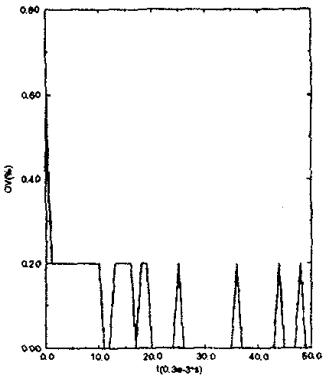

(a)

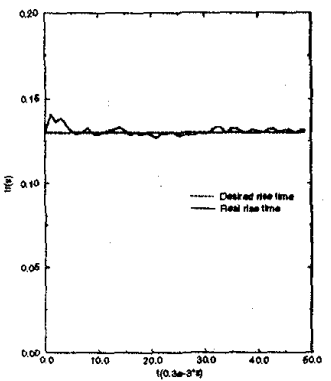

(b)
Figure 7: Experimental evolution of Overshoot and Rise time during the adaptation sequence: (a) Overshoot. (b) Rise time.

time response is achieved in a short number of cycles. The lower part of the figure shows the system responses at the first and third cycles. Figures 7(a) and 7(b) show the evolution of the overshoot and rise time respectively in the same case as figure 6 . The low precision in the measured overshoot is due to a poor encoder resolution. It can be observed that the objectives are accomplished in the proposed scheme: desired rise time $(0.13 \mathrm{~s})$ and low overshoot. Note that the adaptive process is really very quick, providing in a short number of cycles a better control system.

\section{Conclusions}

A fuzzy expert system for the automatic tuning of a Switching Fuzzy Controller for Induction Motors has been presented. A new type of fuzzy controller, based on a PD-like fuzzy and a PI-like fuzzy controllers is used. The control action is weighted between the previous controllers by a fuzzy inference machine which provides a fuzzy division of the control region. Another fuzzy expert system is used to obtain a simple adaptive mechanism for the control system. The complete system acts in a hierarchical way with simple PI-like and PD-like fuzzy controller in the lowest level, a supervisory fuzzy controller in the intermediate level and a fuzzy expert system for self-tuning in the highest level of the hierarchy. Simulation results prove a good performance of the proposed control system, in relation to a simple PD-like fuzzy system or a simple PI-like fuzzy system. Experimental results show a good performance of the controller proposed and that the required specifications are attained by the adaptive process in a shorter number of cycles that the one obtained in the previous paper based on a simple PI-like fuzzy controller.

\section{ACKNOWLEDGMEN'T}

This work has been partially supported by the Spanish Comisión Interministerial de Ciencia y Tecnología under project TAP-0608-C03-03. 
[1] B. K. Bose, Power Electronic and AC Drives, Prentice-Hall Englewood Cliffs, N. J., 1987.

[2] E. Galván, F. Barrero, M. A. Aguirre, A. Torralba, L. G. Franquelo, "A Robust Speed Control of AC Motor Drives based on Fuzzy Reasoning", IAS-93 Annual Meating, pp 2055-2058, Toronto 1993.

[3] Toshiaki Kudor, Kazufumi Ishihara, Haruo Naitoh, "Self-Commissioning for Vector Controlled Induction Motors", IAS-93 Annual Meating, pp 528-535, Toronto 1993

[4] Sayeed A. Mir, Donald S. Zinger, Malik E. Elbuluk, "Fuzzy Implementation of Self Control of Induction Machines" IAS-93 Annual Meating, pp 710717, Toronto 1993

[5] Ichiro Miki, Tatsuo Kumano, Tetsuo Yamada, "Auto-Tuning Method Based on Fuzzy Reasoning for Speed Controller in Vector-Controlled Induction Motor Drives", IAS-93 Annual Meating, pp 718727, Toronto 1993

[6] Amin Suyitno, J. Fujikawa, H. Kobayashi, Yasuhiko Dote, "Variable-Structired Robust Controller by Fuzzy Logic for Servomotors", IEEE Transactions on Industral Electronics, Vol. 40, No. 1, Feb 1993.

[7] Ching-Chang Wong and Shyuan-Ming Feng, "A Switching Type of Fuzzy Controller", FUZZ-IEEE94 Annual Meating, pp 30-33.

[8] Zhuo Li, Shi-Zhong He and Shaoua Tan, "A Refined On-Line Rule/Parameter Adaptive Fuzzy Controller”, FUZZ-IEEE-94 Annual Meating, pp 14721477.

[9] F. Barrero, E. Galván, A. Torralba, L. G. Franquelo, "Fuzzy Selftuning System for Induction Motor controllers", Acepted for presentation in IEEE European Power Electronics, to be held in Seville, Spain, September 1995. 